January 2018

\title{
Information Literacy in the Digital Age: Myths and Principles of Digital Literacy
}

\author{
Bernd W. Becker \\ San Jose State University, bernd.becker@sjsu.edu
}

Follow this and additional works at: https://scholarworks.sjsu.edu/ischoolsrj

Part of the Archival Science Commons, Cataloging and Metadata Commons, Collection Development and Management Commons, Information Literacy Commons, Scholarly Communication Commons, and the Scholarly Publishing Commons

\section{Recommended Citation}

Becker, B. W. (2018). Information Literacy in the Digital Age: Myths and Principles of Digital Literacy. School of Information Student Research Journal, 7(2). https://doi.org/10.31979/2575-2499.070202 Retrieved from https://scholarworks.sjsu.edu/ischoolsrj/vol7/iss2/2

This article is brought to you by the open access Journals at SJSU ScholarWorks. It has been accepted for inclusion in School of Information Student Research Journal by an authorized administrator of SJSU ScholarWorks. Formore information, please contact scholarworks@sjsu.edu. 


\title{
Information Literacy in the Digital Age: Myths and Principles of Digital Literacy
}

\begin{abstract}
Librarians have traditionally served as the champions of information literacy, adopting it as a core principle of the profession and creating a movement that tries to facilitate fair, equal access to knowledge and its creation. There are plenty of publications on this topic, but as the Information Age has become the Digital Age, there also needs to be a discussion of how information literacy is evolving. More specifically, librarians are now finding themselves shouldering the responsibilities of digital literacy alongside traditional approaches to information literacy, especially considering how more and more information needs can only be met via digital resources. This paper serves to add to this discussion by examining the different elements of the two literacies, the myths that surround them, and provide some basic principles of information literacy learning and instruction in the digital age.
\end{abstract}

\section{Keywords}

information literacy, digital literacy

\section{About Author}

Bernd Becker is an Associate Librarian at San Jose State University's Dr. Martin Luther King, Jr. Library. He wears many hats at SJSU. His primary assignment is liaison librarian to the Psychology and the Counselor Education departments, overseeing the information literacy instruction and references needs for those areas. He also serves as the Collection Development Coordinator at King and is a regular author for the Taylor and Francis journal Behavioral \& Social Sciences Librarian. 
Librarians have traditionally served as the champions of information literacy, adopting it as a core principle of the profession and creating a movement that tries to facilitate fair, equal access to knowledge and its creation. There are plenty of publications on this topic, but as the Information Age has become the Digital Age, there also needs to be a discussion of how information literacy is evolving. More specifically, librarians are now finding themselves shouldering the responsibilities of digital literacy alongside traditional approaches to information literacy, especially considering how more and more information needs can only be met via digital resources. This paper serves to add to this discussion by examining the different elements of the two literacies, the myths that surround them, and provide some basic principles of information literacy learning and instruction in the digital age.

One of the first myths of the two literacies is that digital literacy and information literacy are the same thing. Discussion of this perspective depends on one's definition of digital literacy. While the two literacies are very similar, it is arguable that digital literacy evolved from information literacy and that they are not equal in their scope. The traditional perspective of information literacy existed before the digital age, and digital literacy's roots are in information literacy, but there are nuances that keep them separate.

It is important to recognize, however, that a person's definition of digital literacy may reflect their professional or occupational community. Another response someone might have to the digital/information literacy discussion is that digital literacy is literacy. A professor of design, illustration, and photography may feel that digital literacy is the new literacy, implying that we could remove the "digital" aspect from the term since everything within the scope of his field is determined by a certain level of digital literacy competency. In this sense, we must recognize that some people will consider digital literacy a novelty or hobby, while others will see it as a core literacy.

From a library and information science perspective, the Association of College \& Research Libraries (ACRL) states that "Information literacy is the set of integrated abilities encompassing the reflective discovery of information, the understanding of how information is produced and valued, and the use of information in creating new knowledge and participating ethically in communities of learning" (p3, 2016). Similar ideas are also reflected in the American Library Association's (ALA) definition of digital literacy: "Digital literacy is the ability to use information and communication technologies to find, understand, evaluate, create, and communicate digital information, an ability that requires both cognitive and technical skills" (p2, 2013).

It's important to break down the similarities and differences between these two literacies. Side by side, the core components of each are similar. Both definitions are grounded in concepts of finding, understanding, and using the necessary information. But it's the qualities of a digitally literate person that brings the differences between the two literacies to light. The ALA has identified five sets of traits of a digitally literate person (2013).

First, The ALA (2013) considers a digitally literate person as someone who possess the variety of skills -that are both cognitive and technical- required to 
find, understand, evaluate, create, and communicate digital information in a wide variety of formats.

In terms of functions, the ALA (2013) states that a digitally literate person is someone who appropriately and effectively uses diverse technologies to search for and retrieve information, interpret search results, and judge the quality of the information retrieved.

The third aspect of a digitally literate person is that he or she understands the relationships among technology, lifelong learning, personal privacy, and appropriate stewardship of information. Here we see an aspect of the context of the digital information. There's a knowledge about how digital information and technology can affect life beyond the information need. (ALA, 2013)

The aspects of a digitally literate person don't always focus on technical skills, it's also about connections. There is the idea of using these skills and appropriate technologies to communicate and collaborate with peers, colleagues, family, and the general public. A digitally literate person uses these skills to participate actively in civic society and contribute to a vibrant, informed, and engaged community. (ALA, 2013)

These five characteristics of a digitally literate person show how information technology is integrated into the person's life, rather than it just being a set of technical skills, which is what the traditional idea of information literacy gravitated towards. In this sense, digital literacy has become its own literacy. However, digital literacy and information literacy cannot exist without one another.

Another myth that is important to address is the idea that digital natives are by default, digitally literate. The term digital natives is a categorization of a person born or brought up during the age of digital technology. In many ways this leads them to be familiar with computers and the Internet from an early age. The problem is that being familiar and being literate are not necessarily the same thing. This has caused all kinds of stereotypes for digital natives. It's also led to unfair assumptions about those who are far from being digital natives, specifically older adults.

The reality is that everyone struggles with digital literacy. Younger generations might have the technical skills, but lack the refined cognitive skills to find, evaluate, create, and communicate. Older generations might have the cognitive skills, but lack the refined technical skills to find, evaluate, create, and communicate.

No one is born digitally literate, and no one's age will determine their digital literacy skills. This also applies to everyone in between digital natives and the elderly. As library and information professionals, we need to keep these stereotypes at bay. The general population across all ages have different issues with digital literacy. So instead of physical or social demographics, we might consider grouping students and patrons by how ready they are to embrace digital literacy skills.

Fortunately, John Horrigan for the Pew Research Center (2016) published a recent study on digital divides and digital readiness. The new research 
examined the attitudes and behaviors in people's preparedness and comfort in using digital tools, specifically for learning.

The Pew study looked at five main factors: confidence in using computers, facility with getting new technology to work, use of digital tools for learning, ability to determine the trustworthiness of online information, and familiarity with contemporary education tech terms. The analysis of results shows several distinct groups on the spectrum of digital readiness.

In general, about $52 \%$ of the population are Relatively Hesitant to learn in a digital environment, while $48 \%$ are Relatively Prepared to learn in a digital environment. This means about half of the students and patrons we work with are comfortable moving forward, while the other half have generally lower levels of involvement with personal learning activities, lower level of digital skills, and a low level of trust in an online environment.

The Pew research then breaks down each of those cohorts into distinct groups. For the $52 \%$ that are Relatively Hesitant, 14\% of those are Unprepared, $5 \%$ are Traditional Learners, and 33\% are likely to be Reluctant.

The Unprepared is a group with both low levels of digital skills and limited trust in online information. The Unprepared rank at the bottom of those who use the internet to pursue learning, and they are the least digitally ready of all the groups.

The small group of Traditional Learners are active learners, but they use traditional methods to pursue their interests. They are less likely to fully engage with digital tools, because they have concerns about the trustworthiness of online information.

A larger group, The Reluctant have higher levels of digital skills than The Unprepared, but very low levels of awareness of new "education tech" concepts. They also have lower levels of performing personal learning activities of any kind. This is correlated with their general lack of use of the internet in learning.

On the other end of the spectrum, we have about $48 \%$ of the population who are Relatively Prepared to use online tools for learning. The research has broken this cohort into two groups, The Cautious Clickers, and the Relatively Prepared.

The group deemed the Cautious Clickers comprises $31 \%$ of adults. They have tech resources at their disposal, they have trust and confidence in using the internet, and they have a drive to put digital resources to use for their learning pursuits. But they have not ventured into e-learning to the extent the Digitally Ready have and are not as likely to have used the internet for some or all of their learning.

The final group, the Digitally Ready, make up $17 \%$ of adults who are both active learners and confident in their ability to use digital tools for online learning. They are aware of the latest educational technology tools and are more likely to use them in the course of their personal learning.

The Digitally Ready have high demand for learning and use a range of tools to pursue it - including, to an extent significantly greater than the rest of the population, digital outlets such as online courses or extensive online research. 
These categories provide a snapshot of the general population, and the important thing to take away is that we need to start thinking of our patrons or students in terms of where they are on the spectrum of digital readiness, which is reflected in attitudes and experiences, not physical traits such as age.

Another principle to consider is that digital literacy behavior is driven by goals. In a 2015 research study, Michelle DCouto and Serena Rosenhan looked at how students carry out research, what they found can impact how we go about teaching our users about digital literacy. They found that behavior is driven by goals, and categorized learners into four different groups.

First, there's the Gen-Req-er. This is a learner who is driven by the minimum need or requirements. This learner wants the quickest and easiest way to get to the information. They are not interested in learning all the ins and outs of a piece of software. Their digital literacy skills will grow in small, incremental steps as they go through trial and errors in their learning. This is the type of person who might get frustrated with librarians if they try to explain how a program works, or if they try to show them lots of different features in a digital product. Librarians must be very patient when working with this type of person, and realize that the Gen-Req-er might not be ready to learn skills beyond their information need.

The next type of learner is identified as the Domain Learner. This is a person who is driven to learn information about a specific discipline or practice. He or she is ready to invest in the tools and resources connected to a subject. This is a person who is, for example, interested in learning the different tools or websites available for doing a family history and genealogy search. They are going to be in a mode where they're driven to learn and make connections between digital literacy and information literacy as they explore products and features. Digital literacy instruction in this scenario is probably going to be a survey of the different genealogy services and resources that are available in a library and online.

The next type of learner is the Apprentice. This is someone who probably has a good grasp of the information that they need, but librarian can work with them as a specialist. Less time will be spent on covering basic terms and practices, but and more time will be spent on deeper exploration of the features of a digital resource. This is where the librarian can teach how database is indexed, and how to search with deep filters. Information literacy skills will develop as the patron is shown the controlled vocabulary that the database uses and as they are introduced them to more complex search strategies. The content of this type of information literacy instruction of would likely not be appropriate for a Domain Learner, and especially not for a Gen-Req-er.

Finally, there is the learner whose digital literacy behavior is driven by his or her role as a scholar. The Scholar is already an expert, and will continue to build upon years of knowledge and contribution. This person needs to know all the tools and techniques available, and is motivated by advanced learning. It's with these kinds of interactions that the librarian is likely to learn just as much from the learner as they are teaching him or her something new about the tools and resources within the discipline. 
Each of these goals will drive someone's digital literacy behavior. Their goals will help determine the content of your instruction, as well as the pace and scope. Digital literacy isn't always about being an expert, or having to provide an expert level of instruction. Try to tailor information/digital literacy interactions according to the person's needs or goals.

This idea of goals driving digital literacy development is also reflected in the Principle of Three Models of Digital Literacy. This principle comes from the New Media Consortium (NMC, 2016), a community of experts in educational technology who research emerging technology and digital trends.

The NMC wrote a brief on Digital literacy in October 2016 to try to help colleges and universities better understand how to advance digital literacy among students and faculty. In their brief they propose three models of digital literacy: Universal Digital Literacy, Creative Digital Literacy, and Digital Literacy Across Disciplines. Approaching digital literacy in this way will help determine the content of a librarian's digital literacy instruction.

First is the model of Universal Digital Literacy. This of this as a baseline set of practices cuts across the diversity of responses, and it applies to learners and creators of all ages. Universal Digital Literacy means that the learners are familiar with using basic digital tools such as office productivity software, image manipulation, cloud-based apps and content, and basic web content authoring tools.

If a librarian is teaching content that falls under Universal Digital Literacy, they will need to consider that their learners are starting with a low level of digital learning. They will need to be exposed to all the basic terms, concepts surrounding the topic, and instruction will need to be focused on the basic, simple steps.

Then there is the model of Creative Digital Literacy which builds upon Universal Digital Literacy, but emphasizes the production (or creation) of content. Technical skills in this model are more challenging ones that can lead to richer content such as image/video editing and an understanding of device hardware and programming. This model also connects digital practices to online citizenship and behavior by introducing knowledge about privacy, security, and ethics. Creative Digital Literacy isn't separate from Universal Digital Literacy, it's just a model that takes the learner beyond the basics.

For example, if a librarian were teaching a basic workshop about social media tools, he could expand the universal literacy of "how to tweet" to now include a review of Twitter's user agreements which explains that Twitter will immediately own whatever is posted post, and even sell that information to other companies that aggregate and analyze the data.

The NMC also identifies the model of Digital Literacy Across Disciplines. This is the act of embedding digital literacy into the curriculum in a way that is appropriate and unique to each learning context. This is the most crucial form of literacy for many academic librarians. There's no way the library can reach every one of 30,000+ students. However, effective outreach to the teaching faculty to training them how to incorporate digital literacy into their assignments and exercises moves agency away from a single library or librarian, and into the 
different learning communities. This model also allows a learner to connect digital literacy skills to specific subject areas and focuses the instruction.

These three models of digital literacy line up well with the models of learners that were discussed earlier. It is critical to adjust your information/digital literacy instruction so that it reflects the learners' goals and context. But what about the times when the audience is a mixed bag of learning goals and digital readiness? In cases like that, it is a best practice to always teach to the lowest common denominator.

Regardless of the model, information/digital literacy instruction needs to be built around the idea that the librarian is going to be teaching both cognitive and digital skills. Notice the two important traits in the ALA definition of Digital Literacy: "Digital literacy is the ability to use information and communication technologies to find, understand, evaluate, create, and communicate digital information, an ability that requires both cognitive and technical skills" (ALA, p2, 2013).

It is important to recognize that cognitive and technical skills are the fundamental skills in supporting digital literacy. Digital literacy is something much greater than just learning how to use software or digital technology.

The necessary cognitive skills are developed through teaching, while the technical skill as something that is developed through training. This can be considered as the teaching and training approach to digital literacy instruction.

The teaching (cognitive) aspect is addressed as the librarian teaches about the technology necessary to fulfill an information need, such as the context of the information. The instruction is about the organization of the resource and some of the more universal concepts of digital literacy. The librarian is helping the learner understand the information need. This is important because it sets the stage and helps a person put the technical skills in the context of the information need.

Then, pair the teaching aspect with the training. This is the technical components of information/digital literacy instruction, where the learner is trained on how to use the technology. You demonstrate and train the learner to go through the process necessary to reach the information that they need.

This approach to digital literacy instruction fosters experiential learning. It facilitates information retrieval with knowledge about the technology. In this way, the user learns about the information while experiencing an efficient and effective way to use the technology to retrieve the information.

Another approach to addressing the cognitive and technical aspects of digital literacy is to realize that it creates a double learning curve. The patron is having to make progress in learning about their information need as well as their technology need.

First the person is going to have to learn the context of their information. For example, consider a patron who needs to access online databases to locate research in order to write a literature review. First they have to understand the information need, in this case they are going to have to learn about what a literature review is, and what it is not. They're going to have to learn about the components and its scope of a literature review. 
At the same time, or very close to the same time, they're going to be introduced to the technical needs, where they must learn how to use the software (in this case, the databases). They are simultaneously having to process the theory behind the literature review, while learning the technical skills required by the database.

This can immediately lead to frustration, stress, hopelessness, and feelings of stupidity. The double learning curve is one of the biggest obstacles to improving digital literacy skills. To a new user, it will feel like everything is being thrown at them at once, and there's no way they can process all that information at once (and retain it).

One way to work around this experience is to teach like a tutorial. Move through the content slower than you normally would. Keep the lessons short, and include exercises that allow the person to demonstrate what they just learned. Another best practice is to always start instruction by describing the goals of the instruction. This helps the learner understand what the technology is and what it does.

Finally, the information presented should be provided in multiple formats, which leads to the last principle of information/digital literacy instruction. Prepare the instruction or interactions to be delivered in multiple modes. Have the material be available online, provide supplemental handouts with key concepts and steps, and be able to deliver the instruction face-to-face.

Each of these modes will require an adjustment to the instructional content to fit the delivery method, but this is a crucial step in delivering digital literacy instruction. The librarian needs to be sensitive to the different learning styles, and be available to cater to each of them. Whether you are operating within a public, academic, or special library serving children, students, or the general community, information literacy and digital literacy are intertwined in such a way that librarians are having to draw upon a variety of skill and pedagogies. Information literacy is no longer bibliocentric, and the profession must adopt digital literacy principles to remain relevant throughout the Digital Age. 


\section{References}

American Library Association. (2013). Digital Literacy, Libraries, and Public Policy: Report of the Office for Information Technology Policy's Digital Literacy Task Force. Retrieved from http://www.districtdispatch.org/wpcontent/uploads/2013/01/2012_OITP_digilitreport_1_22_13.pdf

Association of College \& Research Libraries. (2016). Framework for Information Literacy for Higher Education. Retrieved from http://www.ala.org/acrl/sites/ala.org.acrl/files/content/issues/infolit/Frame work_ILHE.pdf

D'Couto, M., \& Rosenhan, S.H. (2015). How students research: Implications for the library and faculty. Journal of Library Administration, 55(7), 562-576.

Horrigan, J. B. (2016). Digital Readiness Gaps. Retrieved from http://www.pewinternet.org/2016/09/20/digital-readiness-gaps/

New Media Consortium. (2016). Digital Literacy: An NMC Horizon Project Strategic Brief. Retrieved from http://cdn.nmc.org/media/2016-nmchorizon-strategic-brief-digital-literacy.pdf 